\title{
Temporal Coding by Cochlear Nucleus Bushy Cells in DBA/2J Mice with Early Onset Hearing Loss
}

\author{
Yong Wang and Paul B. Manis \\ Department of Otolaryngology/Head and Neck Surgery, University of North Carolina, 1115 Bioinformatics Building, \\ CB\#7070, Chapel Hill, NC 27599-7070, USA
}

Received: 7 June 2006; Accepted: 27 July 2006; Online publication: 26 October 2006

\begin{abstract}
The bushy cells of the anterior ventral cochlear nucleus (AVCN) preserve or improve the temporal coding of sound information arriving from auditory nerve fibers (ANF). The critical cellular mechanisms entailed in this process include the specialized nerve terminals, the endbulbs of Held, and the membrane conductance configuration of the bushy cell. In one strain of mice (DBA/2J), an early-onset hearing loss can cause a reduction in neurotransmitter release probability, and a smaller and slower spontaneous miniature excitatory postsynaptic current (EPSC) at the endbulb synapse. In the present study, by using a brain slice preparation, we tested the hypothesis that these changes in synaptic transmission would degrade the transmission of timing information from the ANF to the AVCN bushy neuron. We show that the electrical excitability of bushy cells in hearingimpaired old DBA mice was different from that in young, normal-hearing DBA mice. We found an increase in the action potential (AP) firing threshold with current injection; a larger AP afterhyperpolarization; and an increase in the number of spikes produced by large depolarizing currents. We also tested the temporal precision of bushy cell responses to high-frequency stimulation of the ANF. The standard deviation of spikes (spike jitter) produced by ANF-evoked excitatory postsynaptic potentials (EPSPs) was largely unaffected in old DBA mice. However, spike entrainment during a $100-\mathrm{Hz}$ volley
\end{abstract}

Correspondence to: Yong Wang - Department of Otolaryngology/ Head and Neck Surgery - University of North Carolina • 1115 Bioinformatics Building, CB\#7070, Chapel Hill, NC 27599-7070, USA. Telephone: +1-919-966-8926; fax: +1-919-966-7656; email: yong_ wang@med.unc.edu of EPSPs was significantly reduced. This was not a limitation of the ability of bushy cells to fire APs at this stimulus frequency, because entrainment to trains of current pulses was unaffected. Moreover, the decrease in entrainment is not attributable to increased synaptic depression. Surprisingly, the spike latency was $0.46 \mathrm{~ms}$ shorter in old DBA mice, and was apparently attributable to a faster conduction velocity, since the evoked excitatory postsynaptic current (EPSC) latency was shorter in old DBA mice as well. We also tested the contribution of the low-voltageactivated $\mathrm{K}^{+}$conductance $\left(g_{\mathrm{KLV}}\right)$ on the spike latency by using dynamic clamp. Alteration in $g_{\mathrm{KLV}}$ had little effect on the spike latency. To test whether these changes in DBA mice were simply a result of continued postnatal maturation, we repeated the experiments in CBA mice, a strain that shows normal hearing thresholds through this age range. CBA mice exhibited no reduction in entrainment or increased spike jitter with age. We conclude that the ability of AVCN bushy neurons to reliably follow ANF EPSPs is compromised in a frequency-dependent fashion in hearing-impaired mice. This effect can be best explained by an increase in spike threshold.

Keywords: auditory, spike reliability, entrainment, deafness, endbulb of Held

\section{INTRODUCTION}

Many biologically relevant aspects of the auditory environment require the brain to discern features of the acoustic stimulus that occur on a time scale of tens of microseconds. Cells in the central auditory pathways are specialized to retain and even improve 
the auditory timing information that is available from the hair cell. In the anterior ventral cochlear nucleus (AVCN), bushy cells are capable of exquisite phaselocking that, in some cases, is even greater than that of auditory nerve fibers (ANFs) (Smith et al. 1993; Joris et al. 1994; Paolini et al. 2001). To accomplish this task, bushy cells possess synaptic and biophysical specializations (Oertel 1997; Trussell 1999). ANFs give rise to large terminals, the endbulbs of Held, with multiple synaptic contacts that deliver strong synaptic drive to the bushy cell. Postsynaptic AMPA receptor-mediated synaptic currents in bushy cells decay with time constants on the order of $160 \mu$ at $33^{\circ} \mathrm{C}$ (Raman and Trussell 1992; Isaacson and Walmsley 1996; Gardner et al. 1999; Brenowitz and Trussell 2001; Gardner et al. 2001). Bushy cells also have a low-voltage-activated $\mathrm{K}^{+}$conductance ( $g_{\mathrm{KLV}}$ ) that endows these cells with a low resting input resistance and a short membrane time constant (Oertel 1983; Manis and Marx 1991; Reyes et al. 1994; Rothman and Manis 2003b). Together, these preand postsynaptic specializations help ensure a high reliability of postsynaptic spiking during ANF activity, while simultaneously enforcing a short temporal window for excitatory postsynaptic potentials (EPSP) summation.

The temporal processing of sound can be affected by hearing loss. In humans, hearing loss results in poor gap detection and speech discrimination (Nelson and Thomas 1997; Snell and Frisina 2000). In mice, temporal sound processing and sound localization deteriorate in aged hearing-impaired animals (Walton et al. 1998; Heffner et al. 2001; Ison and Allen 2003). DBA mice are one model system that can be used to investigate the effect of earlyonset age-related hearing loss. At 3 weeks of age, DBA mice have normal hearing threshold (Willott and Erway 1998; Zheng et al. 1999); however, by 5 weeks, hearing thresholds are elevated by $\sim 30 \mathrm{~dB}$ for frequencies above $8 \mathrm{kHz}$. We previously found that synaptic transmission at the endbulb of Held was affected by the hearing status of DBA mice, whereas no changes were seen in normal hearing CBA mice (Wang and Manis 2005). Hearing-impaired DBA mice exhibited a reduction in the frequency of spontaneous transmitter release, a decrease in quantal size, and a decrease in release probability. In addition, the decay time course of spontaneous EPSCs was slower and the voltage-dependent rectification of EPSC decreased, suggesting a change in the subunit composition of the postsynaptic AMPA receptors (Wang and Manis 2005). On the other hand, minor changes were seen in the intrinsic properties of the cells, consistent with results reported with cochlear ablation in rats and chicks (Francis and Manis 2000; Lu et al. 2004).
The changes in synaptic transmission in older DBA mice suggested that there might be a corresponding functional degradation in the ability of bushy neurons to convey high-frequency, precise temporal information to higher auditory centers. To test this hypothesis, we recorded from bushy cells while presenting shocks at a high rate to the ANF in a brain slice preparation. We measured spike latency, spike jitter and spike entrainment as well as EPSC latency and depression in the high frequency (HF) regions of the AVCN, in both 22- and 45-day-old DBA mice. We also tested bushy cells from the same regions of the AVCN in age-matched CBA mice that show no hearing loss.

\section{MATERIALS AND METHODS}

\section{Animals and hearing tests}

DBA/2J and CBA/Caj mice (Jackson Lab, Bar Harbor, ME) between 20 and 57 days were used in these experiments. All animal protocols were approved by the Institutional Animal Care and Use Committee at the University of North Carolina at Chapel Hill. DBA/ 2J mice older than 40 days were found to have little or no Preyer's reflex in response to a hand clap; CBA mice had a normal reflex regardless of age. To provide an objective measure of hearing thresholds, a subset of mice were tested for auditory brainstem evoked responses (ABR) to clicks immediately prior to preparing brain slices. For these measurements, the mouse was anesthetized intraperitoneally (i.p.) with Avertin $(0.15 \mathrm{ml} / 10 \mathrm{~g} \mathrm{wt})$. A small incision was made in the pinna to allow better access to the ear canal, and the mouse was placed in an acoustically isolated chamber (ENV-018M, MED Associates, St. Albans, VT, USA). The animal's temperature was maintained at $37^{\circ} \mathrm{C}$ via a thermostatically controlled feedback system (Harvard Apparatus, Holliston, MA, USA). An electrostatic speaker (TDT ES-1), with a 1.5-cm-long polyethylene tube was abutted against the ear canal to make a closed acoustic system. Recording electrodes were placed at the vertex and mastoid, with a remote ground under the skin in the rump area. Signals were amplified $10,000 \times$ with a Grass-Telefactor P511J amplifier, and bandpass-filtered from 100 to $3000 \mathrm{~Hz}$. ABR responses were averaged with a Tucker-Davis (Gainesville, FL, USA) System-3 RP2.1 processor controlled by a Matlab (Mathworks, Natick, MA, USA) routine. Stimuli were generated through the RP2.1 and passed through a PA5 attenuator prior to delivery to the speaker amplifier. A series of responses to clicks $(0.5-\mathrm{ms}$ rectangular pulses generated by the RP2.1) were collected at 5-dB intensity steps, over a 70to $80-\mathrm{dB}$ range. Click polarities were alternated on sequential trials, and the waveforms averaged. This 
allowed us to minimize the contribution of the cochlear microphonics to the ABR, and to focus on the components of the waveform generated by the central pathways. ABRs were analyzed by plotting the amplitude of each peak against stimulus intensity. Two independent observers then estimated the threshold as the lowest intensity at which the response was clearly discernible. Immediately after the ABR measurements, brain slices of the AVCN were prepared.

\section{Slice preparation}

Slices of cochlear nucleus were prepared as previously described (Oertel 1983; Wang and Manis 2005). Briefly, mice were anesthetized with ketamine $(100 \mathrm{mg} / \mathrm{kg}) /$ xylazine (10 mg/kg, i.p.), and decapitated. The brainstem, including the cochlear nucleus, was immediately harvested and immersed in prewarmed $\left(34^{\circ} \mathrm{C}\right)$ dissection artificial cerebrospinal fluid (ACSF), which differed from standard ACSF by containing low $\mathrm{Ca}^{2+}$ and high $\mathrm{Mg}^{2+}\left(0.1 \mathrm{mM} \mathrm{CaCl}_{2}\right.$ and $\left.3.7 \mathrm{mM} \mathrm{MgSO} 4\right)$. The standard ACSF contains (in $\mathrm{mM}$ ): $122 \mathrm{NaCl}, 3$ $\mathrm{KCl}, 1.25 \mathrm{KH}_{2} \mathrm{PO}_{4}, 20$ glucose, $25 \mathrm{NaHCO}_{3}, 2 \mathrm{Na}$ pyruvate, 3 myo-inositol, 0.4 ascorbic acid, $2 \mathrm{CaCl}_{2}, 2$ $\mathrm{MgSO}_{4}$, and was bubbled with $95 \% \mathrm{O}_{2}$ and $5 \% \mathrm{CO}_{2}$ to a $\mathrm{pH}$ of 7.4. The tissue block containing the cochlear nucleus was trimmed and mounted on a cutting block. Parasagittal sections 200-250 $\mu \mathrm{m}$ thick that included the cochlear nucleus were prepared by using a vibratome. Slices were incubated for at least $30 \mathrm{~min}$ at $34^{\circ} \mathrm{C}$, and then secured in the recording chamber with nylon netting in flowing ACSF (3-5 $\mathrm{ml} / \mathrm{min}$ ).

All recordings in this paper were made from cells in the HF dorsal third of the AVCN (excluding the granule cell domain). The dorsal third of the nucleus was defined by the trajectory of the ANFs from the nerve root region (Wang and Manis 2005). Based on the mouse cochlear frequency map and its projection onto the AVCN (Ehret 1983; Berglund and Brown 1994; Muller et al. 2005), cells in the region we targeted would be expected to have best frequencies above $25 \mathrm{kHz}$.

\section{Electrophysiological recordings}

AVCN neurons were visualized with a water immersion objective $(40 \times)$ using Nomarski differential interference contrast optics on a Zeiss FS Axioskop (Zeiss, Oberbochen, Germany). To enhance image contrast in slices from older animals, we used white light, closed the field diaphragm nearly all the way, and aligned the condenser slightly eccentrically (Kachar 1985; Gardner et al. 2001). Patch electrode pipettes (3-8 M $\Omega$ ) were pulled from borosilicate glass (KG-33, Garner Glass) with a Sutter P2000 puller (Sutter Instruments, San Francisco, CA, USA). Pipettes were coated with
Sylgard 184 (Dow Corning, Midland, MI, USA) before use. The standard electrode solution contained (in $\mathrm{mM}$ ): $110 \mathrm{~K}$ gluconate, $4 \mathrm{NaCl}, 20 \mathrm{KCl}, 10$ HEPES, 0.2 EGTA, $4 \mathrm{Mg}^{2+}$-ATP, 10 creatine phosphate, and 0.3 GTP. The $\mathrm{pH}$ was adjusted to 7.2 with $\mathrm{KOH}$, and the final osmolarity was $\sim 295 \mathrm{mOsm}$. Evoked EPSC recordings (with the exception of spike latency test) were made with a $\mathrm{Cs}^{+}$-based electrode solution containing QX314 (Tocris Cookson, Bristol, UK), in order to minimize contamination from potassium and sodium conductances. This solution contained (in mM) $125 \mathrm{CsMeSO}_{3}$, $15 \mathrm{CsCl}, 5$ EGTA, 10 HEPES, $4 \mathrm{Mg}^{2+}$-ATP, 10 creatine phosphate, 0.3 GTP, and 2-5 mM QX314; the $\mathrm{pH}$ was adjusted to 7.2 with $\mathrm{CsOH}$. In some experiments, $0.1 \%$ Alexa Fluor488 (Molecular Probes, Eugene, OR, USA) was added to aid cell visualization and identification. Except where indicated, recordings were performed at room temperature $\left(22-25^{\circ} \mathrm{C}\right)$ using an Axopatch 200B (Axon Instruments, Foster City, CA) under the control of in-house software written in Matlab. Whole-cell access resistance was less than $15 \mathrm{M} \Omega$ and compensated to greater than $70 \%$ on-line with a $20-\mu$ s lag time. For dynamic clamp, addition or subtraction of the $g_{\mathrm{KLV}}$ was accomplished by using the Real-Time Linux Dynamic Clamp (RTLDC, V2.2) system developed by Dorval et al. (2001). The dynamic clamp system utilized a separate acquisition computer (Intel Pentium P4, 2.8 GHz) running Linux (Fedora 3.0, RedHat, Raleigh, NC, USA) and a 16-bit National Instruments A/D-D/A card (NI6052E), in parallel with the primary acquisition system, and was operated at $20-40 \mathrm{kHz}$. The parameters of $g_{\mathrm{KLV}}$ were based on the kinetic model of Rothman and Manis $(2003 \mathrm{~b}, \mathrm{c})$ at $22^{\circ} \mathrm{C}$. We adjusted $g_{\mathrm{KLV}}$ over a range of values, while examining the response of the cell to current pulses injected by the primary recording system, or to stimuli delivered to the AN. To record low-voltage-activated $\mathrm{K}^{+}$current, $0.5 \mu \mathrm{M}$ tetrodotoxin (Sigma, St Louis, MO, USA) and $10 \mu \mathrm{M}$ ZD7288 (Sigma) were added to the ACSF to block voltage-gated $\mathrm{Na}^{+}$current and hyperpolarization activated cation conductances. The addition of $30 \mathrm{nM} \alpha$-dendrotoxin (Alomone, Jerusalem, Israel) was used to block $g_{\mathrm{KLV}}$.

EPSC threshold was measured by varying the ANF stimulus strength. The stimulus strength was then adjusted to be $1.5-2 \times$ threshold in order to elicit reliable minimal EPSCs, while at the same time avoiding activation of additional inputs to the cell. Only cells with a clear all-or-none minimal EPSCs of more than $2 \mathrm{nA}$ were selected for analysis; these responses are typical of bushy cells in AVCN (Isaacson and Walmsley 1995).

To test the consequences of high-frequency deafness, responses of bushy cells to trains of auditory nerve shocks were examined in current clamp. The auditory nerve root was stimulated with a train of 20 pulses for 20 trials with intertrial interval of 5-8 
seconds. The stimulus rates used were 100,200 , and $300 \mathrm{~Hz}$ with shock intensity at $1.5-2 \times$ response threshold.

\section{Data analysis}

The resting membrane potential (RMP) of each cell was adjusted by $-12 \mathrm{mV}$ to account for the liquid junction potential between the pipette internal gluconate solution and the bath ACSF; no correction was made when $\mathrm{CsMeSO}_{3}$-containing electrodes were used. The input resistance was measured as the maximum slope of the current-voltage $(I-V)$ curve for voltages $0-40 \mathrm{mV}$ negative to the RMP. $I-V$ rectification around the RMP was calculated by fitting the $I-V$ relationship with a polynomial function and calculating the ratio of the slopes of the polynomial function at $\pm 100 \mathrm{pA}$. The membrane time constants were estimated from fits of double exponential functions to small hyperpolarizing current pulses, by using a Levenberg-Marquardt algorithm. The slower of the two time constants representing the charging of somatic membrane is reported in Table 1. The shape of the AP was quantified by measuring spike height, spike width at half-height, and the maximum rising and falling rates using the approach described by Francis and Manis (2000).

Spike latency was measured from the onset of each auditory nerve shock to the peak of the AP. The latency to the spike peak was used, rather than a threshold crossing or detection of an inflection point, because the APs changed shape and size during the stimulus train. Spike jitter (of a given pulse in the train) was calculated as the standard deviation of spike latencies over 20 repetitive trials. The entrainment index was calculated for each shock in the train as the fraction of trials on which the cell spiked (Fig 2C). Synaptic depression was calculated as the ratio of a given EPSC amplitude to the first EPSC.

Statistical significance $(p<0.05)$ was determined by using unpaired Student's $t$-test or two-way analysis of variance (ANOVA), where appropriate, using Prism V3 (GraphPad Software, San Diego, CA, USA). All other analyses were carried out using custom scripts in Matlab. Data are shown as means \pm SE.

\section{RESULTS}

We first confirmed that the hearing loss previously reported in DBA mice (Willott and Bross 1996; Zheng et al. 1999) was present in the mice used in this study. The click-evoked ABR thresholds in a subset of the DBA mice aged 40 days and older (average 45 days) were about $20 \mathrm{~dB}$ higher than the thresholds of mice $\sim 22$ days old (Fig. 1B). In contrast, ABR thresholds were not different between young $(\sim \mathrm{P} 22)$ and old $(\sim \mathrm{P} 45)$ CBA mice.

Comparison of electrical excitability in mice with and without hearing loss

We characterized the electrical excitability and passive membrane properties of bushy cells in the high frequency regions of the AVCN. The discharge patterns of the majority of AVCN neurons to current pulses can be assigned to one of two previously described classes, type I and type II (Oertel 1983). Type I responses are characterized by repetitive firing with a regular interspike interval, and a linear subthreshold $I-V$ relationship. In contrast, type II cells fire one or two APs at the onset of a depolarizing

TABLE 1

\begin{tabular}{|c|c|c|c|c|}
\hline \multicolumn{5}{|c|}{ Neuronal parameters of AVCN bushy cells in DBA and CBA mice } \\
\hline & \multicolumn{2}{|c|}{ DBA (mean \pm SE) } & \multicolumn{2}{|c|}{ CBA (mean $\pm \mathrm{SE})$} \\
\hline & HF Old $(n=22)$ & HF Young $(n=15)$ & HF Old $(n=9)$ & HF Young $(n=10$ \\
\hline $\mathrm{RMP}(\mathrm{mV})$ & $-64.3 \pm 0.8$ & $-66.0 \pm 1.7$ & $-65.2 \pm 1.1$ & $-64.1 \pm 0.8$ \\
\hline$R_{\text {in }}(\mathrm{M} \Omega)$ & $143.2 \pm 7.7$ & $142.5 \pm 9.4$ & $131.4 \pm 19.5$ & $139.7 \pm 9.8$ \\
\hline Membrane time constant (ms) & $1.71 \pm 0.14$ & $1.85 \pm 0.21$ & $1.85 \pm 0.36$ & $1.90 \pm 0.23$ \\
\hline IV rectification (slope ratio at $\pm 100 \mathrm{pA}$ ) & $0.72 \pm 0.02$ & $0.67 \pm 0.04$ & $0.66 \pm 0.04$ & $0.70 \pm 0.04$ \\
\hline AP height (mV) & $53.9 \pm 1.4$ & $53.4 \pm 3.2$ & $54.13 \pm 2.5$ & $53.8 \pm 2.7$ \\
\hline AP half-width (ms) & $1.36 \pm 0.09$ & $1.56 \pm 0.13$ & $1.51 \pm 0.20$ & $1.66 \pm 0.16$ \\
\hline Max rising rate of spike $(\mathrm{mV} / \mathrm{ms})$ & $87.4 \pm 7.6$ & $75.7 \pm 7.1$ & $83.5 \pm 12.5$ & $86.5 \pm 4.2$ \\
\hline Max falling rate of spike $(\mathrm{mV} / \mathrm{ms})$ & $44.1 \pm 6.7$ & $31.7 \pm 4.3$ & $37.9 \pm 10.9$ & $29.2 \pm 10.9$ \\
\hline $\mathrm{AHP}(\mathrm{mV})$ & $6.9 \pm 0.4^{* *}$ & $4.1 \pm 0.5$ & $4.3 \pm 0.9$ & $3.6 \pm 0.7$ \\
\hline AP threshold I (pA) & $166.7 \pm 22.1 *(n=24)$ & $108.0 \pm 12.5(n=25)$ & $161.1 \pm 26.1$ & $131.3 \pm 13.2$ \\
\hline AP \# (at $I=+300 \mathrm{pA})$ & $5.6 \pm 1.0^{*}$ & $3.2 \pm 0.9$ & $1.3 \pm 0.2$ & $2.1 \pm 0.7$ \\
\hline
\end{tabular}

${ }^{*} p<0.05 ;{ }^{* *} p<0.001, t$-test. No significant difference was observed for all parameters measured between young and old CBA mice. 

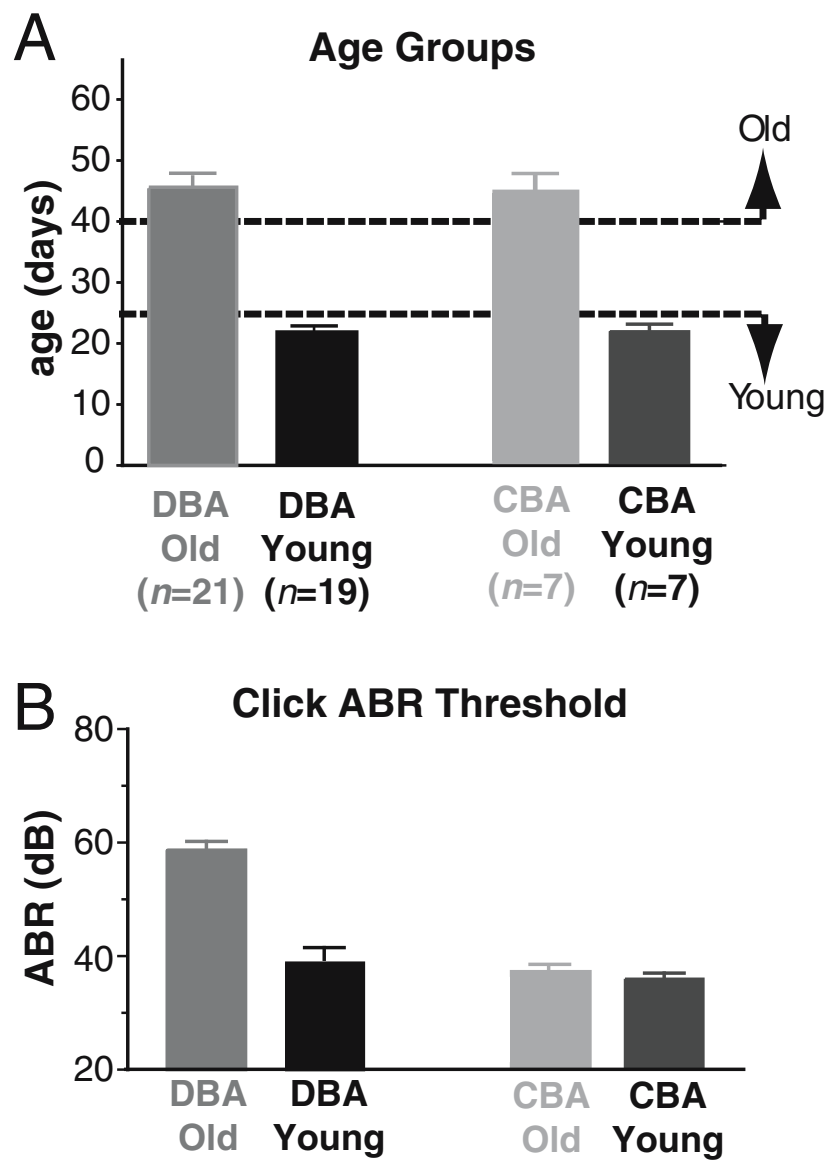

FIG. 1. Animal age groups and their hearing thresholds. (A) Animals younger than 25 days were considered young, whereas animals older than 40 days were considered old. (B) Thresholds of click evoked auditory brainstem response (ABR) from young and old DBA as well as CBA mice. The click levels were expressed in $\mathrm{dB}$ relative to an arbitrary level that was constant across all experiments. Old DBA mice have elevated ABR thresholds.

current pulse (Fig. 2A). The $I-V$ relationship shows rectification around the resting potential, with a shallower slope of the $I-V$ function for voltages positive to rest. The principal cell classes of the AVCN, the spherical and globular bushy cells (Osen, 1969; Brawer et al., 1974) have been previously identified as generating the type II discharge pattern (Wu and Oertel 1986). In the remainder of this paper, we report results from only type II cells.

As reported previously in cochlear-ablated rats (Francis and Manis 2000), chickens (Lu et al. 2004), and in hearing-impaired DBA mice at $33^{\circ} \mathrm{C}$ (Wang and Manis 2005), the passive electrical properties (RMP, input resistance, and membrane time constant) of type II cells were little affected by age or hearing status (Table 1). In addition, the AP shape (as measured by the rising and falling slope, halfwidth, and peak height) was not statistically different between young and old DBA mice. Similarly, no differences in the passive membrane properties nor
A

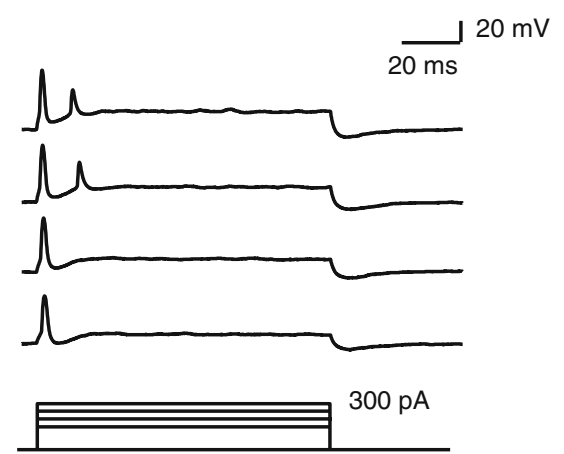

B
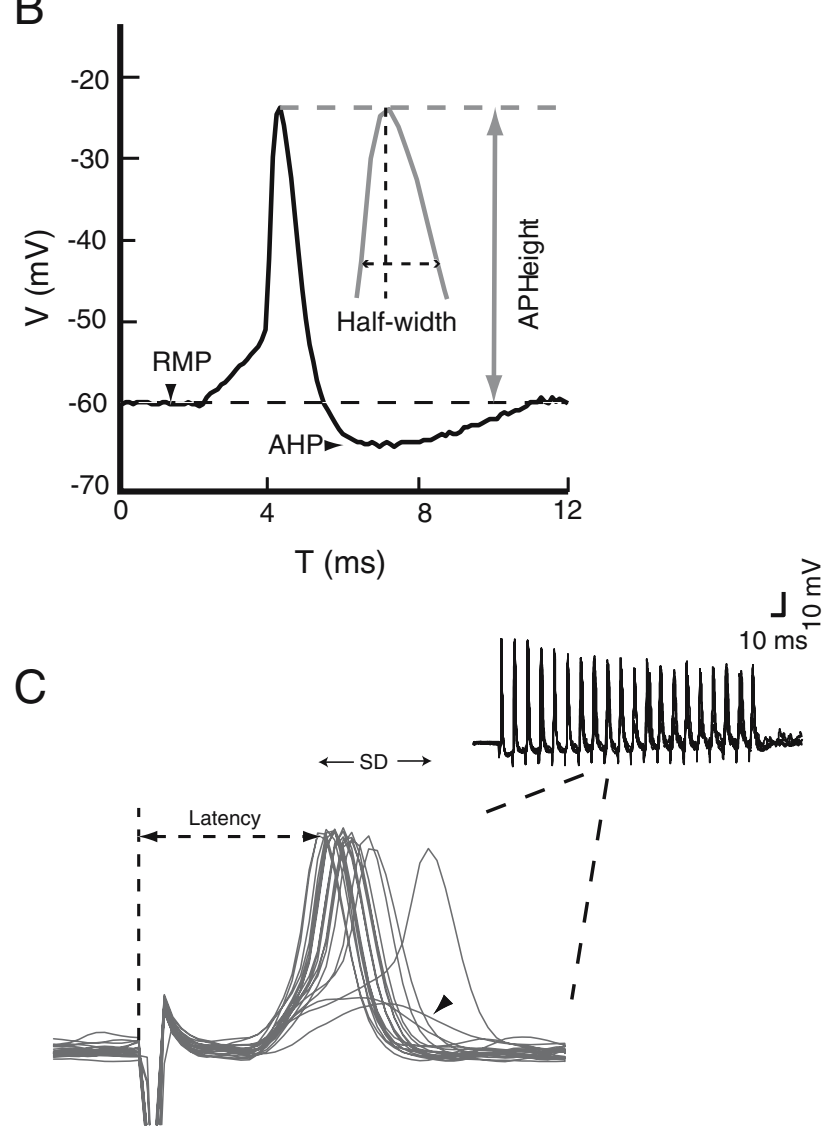

FIG. 2. Intrinsic excitability. (A) Type II cell response to a series (150-300 pA) of depolarizing current injection. Bushy neurons typically respond with 1-2 spikes at the onset of current injection. (B) Parameters used to quantify action potential shape. AP height was the difference between resting membrane potential and spike voltage at the peak. AP width was measured at half-height. The maximum rising and falling rates were calculated from the first derivative of the voltage waveform. (C) Type II cell responses to auditory nerve shocks. A train of 20 suprathreshold shocks was delivered to the auditory nerve root at 100, 200, and $300 \mathrm{~Hz}$. Trains were repeated 20 times with intertrial interval of 5 s. Spike latency was measured from the onset of a shock to the peak of the postsynaptic action potential. For each shock in the train, spike temporal jitter was calculated as the standard deviation of the spike latency over 20 trials. Spike entrainment (of a given pulse in the train) was calculated as the fractional number of spike responses over 20 trials. Notice occasional EPSPs that failed to evoke action potentials (arrowhead). 
in the active electrical behavior were seen between young and old CBA mice.

However, a few aspects of the electrical excitability were different between the old, impaired-hearing and the young, normal-hearing DBA mice. First, the action potential afterhyperpolarization (AHP) was significantly deeper in old than in young DBA mice. Second, similar to that found at $33^{\circ} \mathrm{C}$ (Wang and Manis 2005), the current required to elicit an AP in old DBA mice was larger than that in young DBA mice. Third, although the type II cells always responded with single spikes when tested with small current pulses, larger depolarizing currents could drive multiple spikes in a subset of cells. Multiple spiking was especially predominant in old DBA mice (Table 1). Thirteen of the 22 cells in old DBA mice had more than 2 spikes in response to $+300 \mathrm{pA}$ current injection, whereas only 4 of 15 cells in young DBA showed $>2$ spikes. In contrast, only 1 of 10 young CBA and 0 of 9 old CBA cells responded with $>2$ spikes to the $+300 \mathrm{pA}$ current injection. The presence of multiple spikes with larger currents suggests a weaker low-voltage-activated $\mathrm{K}^{+}$ conductance (Brew and Forsythe 1995; Rothman and Manis 2003b, c).

\section{Response latencies}

We previously reported that endbulb synapses in the high frequency regions of older DBA had lower release probability and smaller and slower spontaneous miniature EPSCs (Wang and Manis 2005). This led us to hypothesize that the decreased efficacy of synaptic transmission would decrease the ability of bushy cells to fire with the same temporal precision
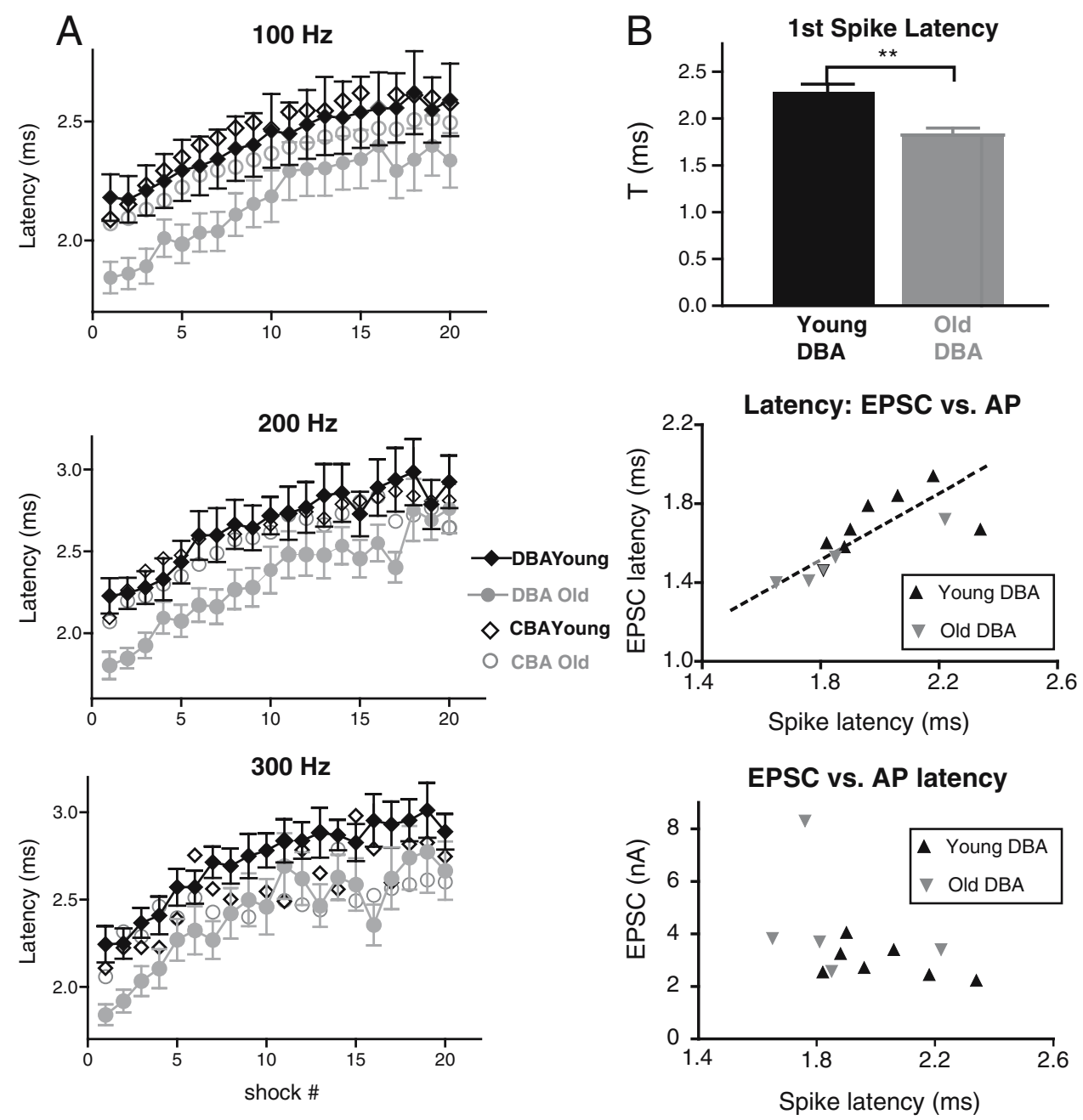

FIG. 3. Spike latency. (A) Spike latency was plotted for shock trains delivered at 100, 200, and $300 \mathrm{~Hz}$. For clarity, error bars are omitted in the plots for CBA data. The spike latencies from old DBA mice were shorter compared to those from young DBA as well as CBA mice. (B) The action potential latency for the first shock stimulus in the train was different between young and old DBA mice (top panel). In a different set of cells, both AP latency (in current clamp) and evoked EPSC latency (in voltage clamp) were recorded from the same cells. There was a strong correlation between spike latency and EPSC latency $(r=0.72, p<0.01$; middle panel). However, action potential latency was not correlated to the EPSC amplitude (lower panel). 
as the ANF. To test this hypothesis, we measured spike latency, spike timing jitter, and spike entrainment in response to short trains of ANF shocks at 100, 200, and $300 \mathrm{~Hz}$ (Fig. 2C). In cells from both DBA and CBA mice of all ages, AP latencies increased within a train of 20 shocks to the ANFs. AP latency was shorter in old than in young DBA mice at all three shock frequencies $(p<0.0001 ; n=11,13$; twoway ANOVA) (Fig. 3A). The latency of the first spike in the train was $2.28 \pm 0.08 \mathrm{~ms}(n=16)$ in young DBA and $1.82 \pm 0.07 \mathrm{~ms}(n=16)$ in old DBA mice $(p<0.001$; Fig. 3B, top panel). In contrast, CBA mice showed no age-related difference in first spike latency (young: $2.10 \pm 0.14 \mathrm{~ms} ; n=7$ vs. old: $2.07 \pm 0.10 \mathrm{~ms}, n=7, p=0.86$ ). Moreover, the latencies in both young and old CBA mice were comparable to those in young DBA mice.
We tested whether the shorter spike latency in the older DBA mice arose from an increase in axonal conduction velocity and/or a shorter synaptic delay by directly measuring the latency of evoked EPSCs in voltage clamp. In a different set of cells, we measured both spike latency (in current clamp) and the underlying EPSC (in voltage clamp) in the same cells, and found that there was a linear correlation between spike latency and EPSC latency (Fig. 3B, middle panel, $r=0.72$, $p=0.002)$. The EPSC latency of high-frequency cells from young DBA was $1.73 \pm 0.05 \mathrm{~ms}(n=7)$, whereas the latency from old DBA mice was $1.50 \pm 0.06 \mathrm{~ms}(n=5$, $p=0.016)$. In contrast, EPSC amplitude was not correlated with AP spike latency (Fig. 3B, lower panel).

We also considered whether the low-voltageactivated $\mathrm{K}^{+}$conductance contributed to the spike

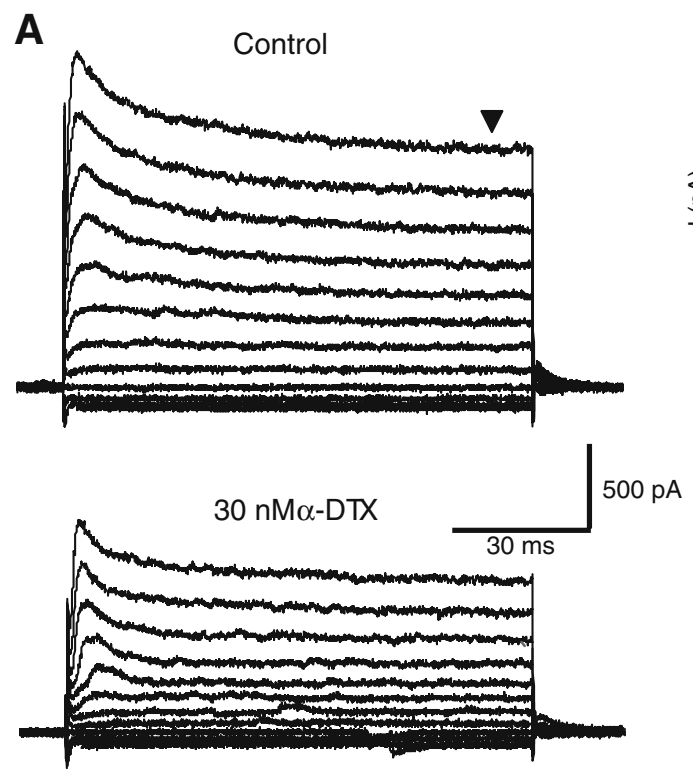

B
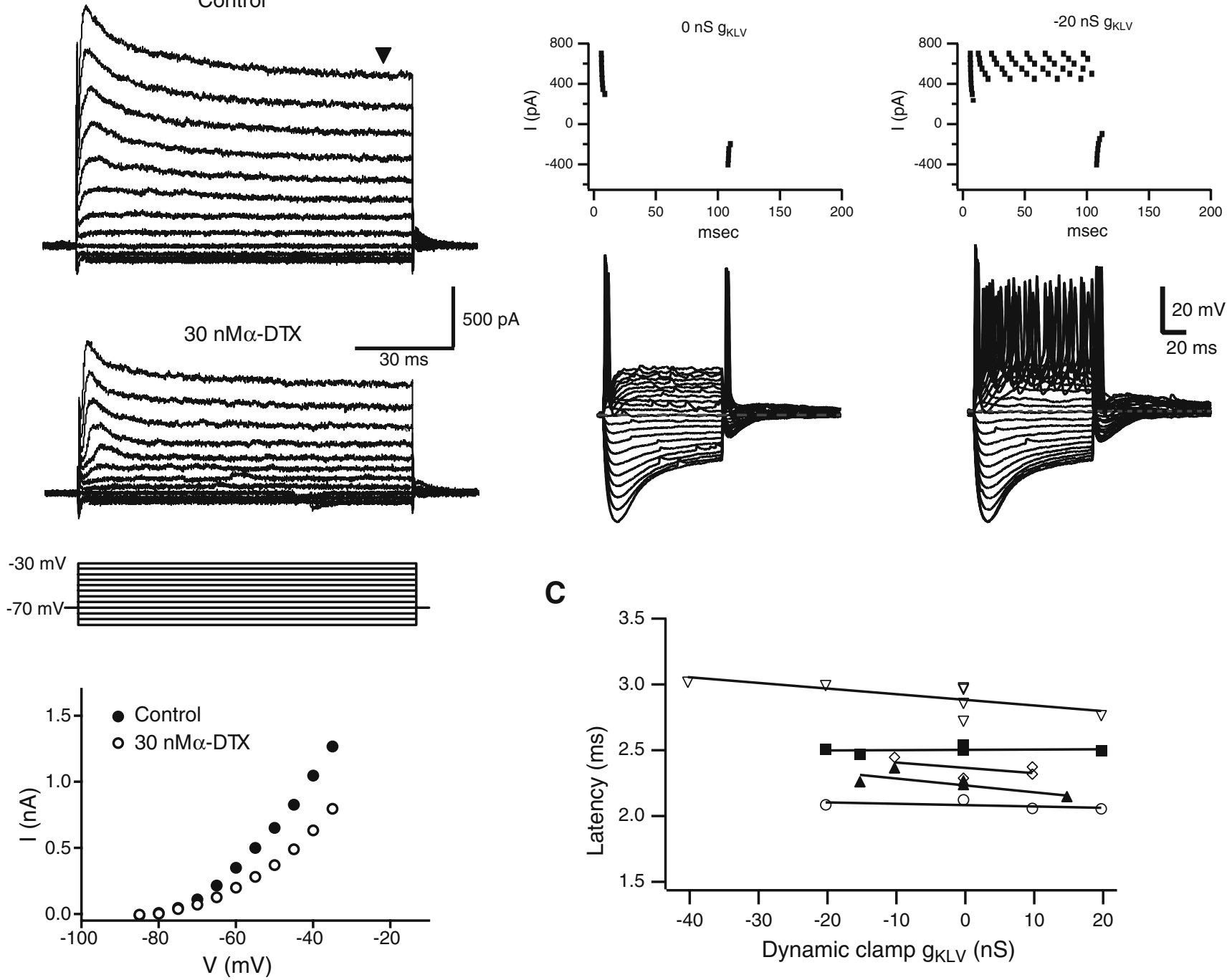

FIG. 4. Effect of $g_{\mathrm{KLV}}$ on spike latency. (A) Total outward $\mathrm{K}^{+}$currents recorded in the relatively negative voltage range -85 to $-30 \mathrm{mV}$ from a bushy cell. Addition of $30 \mathrm{nM} \alpha$-dendrotoxin reduced the amplitude of the steady-state current (measured at the end of the voltage steps, $\mathbf{\nabla})$. (B) Subtracting $20 \mathrm{nS}, g_{\mathrm{KLV}}$ converted a bushy cell from single onset spike response to multiple spiking when challenged with large depolarizing currents. Top panels: raster plots of different trials with injected currents ranging from -400 to $600 \mathrm{pA}$ in $50-\mathrm{pA}$ steps. (C) No significant shift in spike latency was observed when altering $g_{K L V}$ between -20 and $+20 \mathrm{nS}$. 
latency because $g_{\mathrm{KLV}}$ is partially active during rest and would affect the membrane charging time constant, which could influence the time for the EPSP to reach spike threshold. To test this, we first showed that the low voltage activated $\mathrm{K}^{+}$conductance existed in AVCN bushy cells in mice (Fig. 4A; also see Cao and Oertel 2006). In this sample cell, addition of $30 \mathrm{nM}$ of $\alpha$-dendrotoxin, a selective Kv1.1 and 1.2 channel blocker, reduced the total slope conductance (between -70 and $-50 \mathrm{mV}$ ) of steady-state $\mathrm{K}^{+}$current measured at the end of the 100-ms pulse by about $50 \%$ (from 27.5 to $15.0 \mathrm{nS}$ ). The slope conductance $(-70$ to $-50 \mathrm{mV})$ of total steady-state $\mathrm{K}^{+}$current was $28.0 \pm 0.5 \mathrm{nS}(n=2)$ at $33^{\circ} \mathrm{C}$. The -70 to $-50 \mathrm{mV}$ slope conductance of $\mathrm{K}^{+}$was $18.0 \pm 0.7 \mathrm{nS}(n=3)$ at $22^{\circ} \mathrm{C}$; estimate of the magnitude of $g_{\mathrm{KLV}}$ using tail current analysis (based on methods used by Manis and Marx, 1991) showed half-activation $V_{0.5}=-48.3 \pm 3.8 \mathrm{mV}$, and the total conductance was $13.3 \pm 1.0 \mathrm{nS}(n=3)$. We then directly altered the $g_{\mathrm{KLV}}$ in bushy cells by employing a real-time dynamic conductance clamp with $g_{\mathrm{KLV}}$ kinetic parameters adopted from Rothman and Manis (2003b, c). The amount of conductance (typically $\pm 20 \mathrm{nS}$ ) subtracted/added altered cell responses between single spiking and multiple spiking when injected with $\geq 300 \mathrm{pA}$ depolarizing currents (Fig. 4A). These behaviors were reminiscent of what had been observed from bushy cells in young and old DBA mice (Table 1). Surprisingly, changing $g_{\mathrm{KLV}} \mathrm{did}$ not consistently shift spike latency (Fig. 4B). From these experiments, we conclude that shorter spike latencies in old DBA mice are not caused by differences in $g_{\mathrm{KLV}}$, but rather by changes in conduction velocity and/or synaptic delay.

Spike jitter

Spike jitter was measured as the standard deviation of the spike latencies for a given pulse in the train over 20 trials. The first spike jitter was not significantly different between young and old DBA mice $(0.096 \pm 0.015 \mathrm{~ms}$, $n=16$ vs. $0.086 \pm 0.020 \mathrm{~ms} ; n=16$; Fig. $5 \mathrm{~B}$ ). The first
A
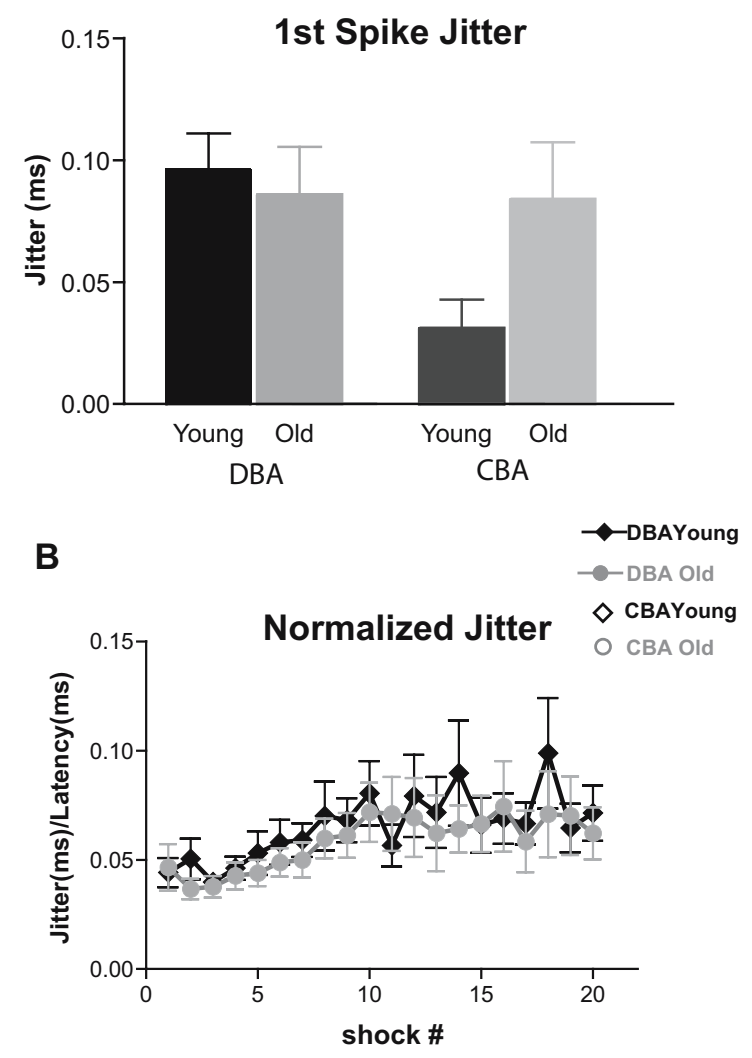
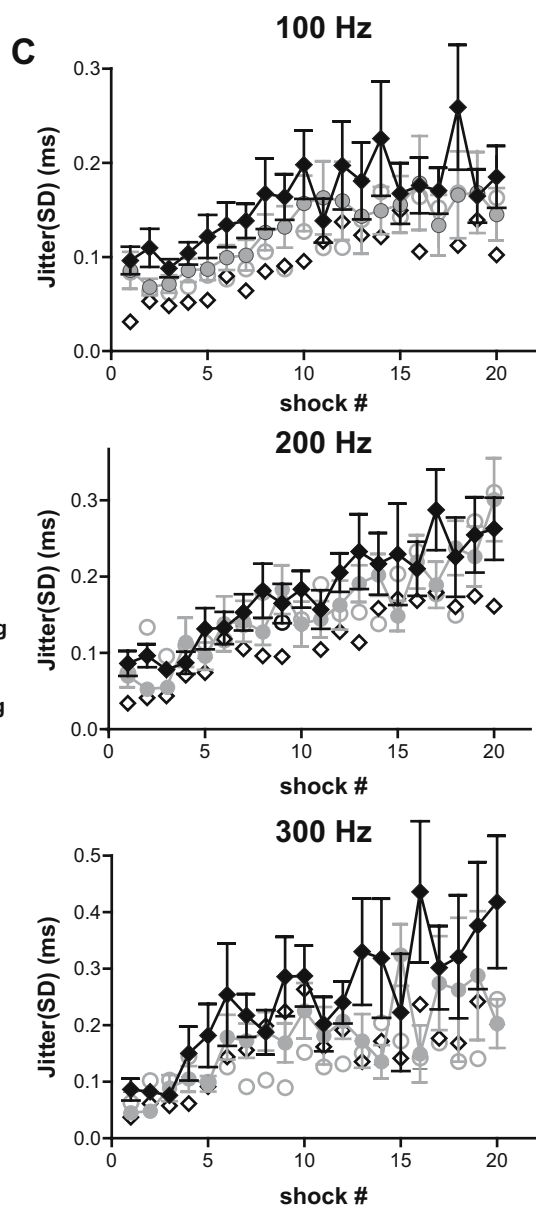

FIG. 5. Spike timing jitter. (A) There was no difference in the first spike jitter between young and old DBA mice. Young CBA mice tended to have smaller first spike jitter, although this was not significant. (B) Normalized spike jitter in DBA mice for shocks delivered at 100 Hz. When spike jitter was normalized to the corresponding spike latency in the train, no difference was observed between young and old DBA mice. (C) Group data of spike jitter at 100, 200, and $300 \mathrm{~Hz}$ shock frequencies. Spike jitter was slightly better in old than young DBA mice in all three shock frequencies. The spike jitter became progressively worse and varied more widely within the train for all shock frequencies. 
A

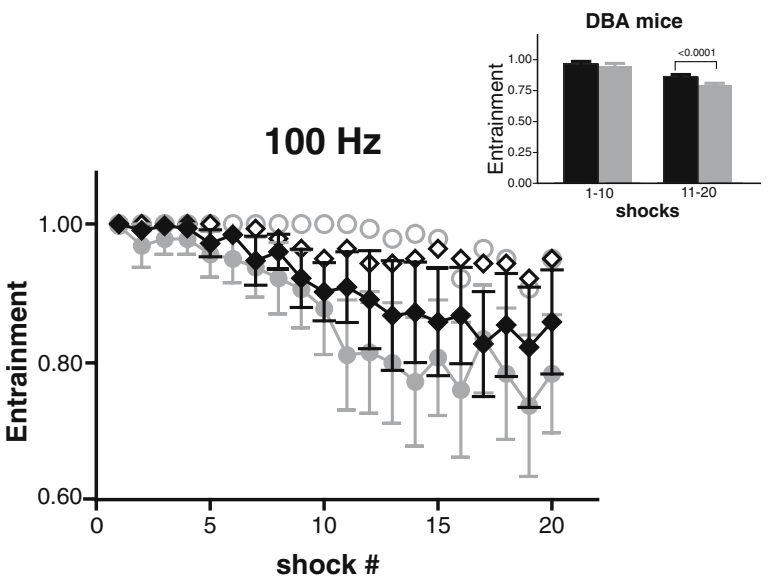

B

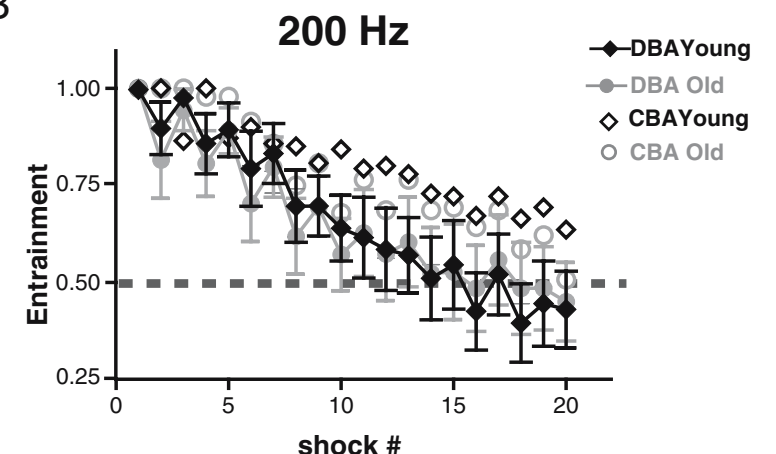

C

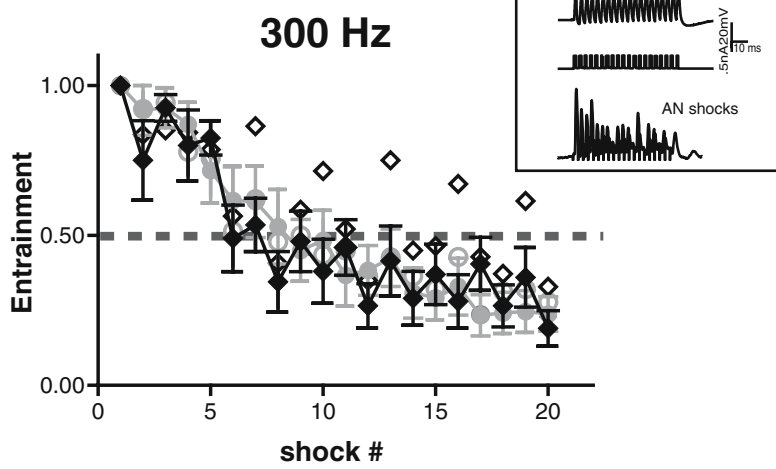

FIG. 6. Spike entrainment. (A) At $100 \mathrm{~Hz}$, there was a significant difference in entrainment between young and old DBA mice. The mean entrainment for the 11 th-20th shocks was significantly lower in old DBA mice than in young DBA mice (inset), but not significantly different between young and old CBA mice. (B) Entrainment at $200 \mathrm{~Hz}$. A larger entrainment decline was seen at $200 \mathrm{~Hz}$ shock (notice the different ordinate scale). No difference in entrainment was observed between young and old DBA mice. (C) Entrainment at $300 \mathrm{~Hz}$. Despite an entrainment index below 0.5, cells continue to show reliable firing with current injection (inset). The interaction between synaptic depression and postsynaptic spike refractory produces an alternating pattern of spikes. Inset: responses to current pulses (top) and auditory nerve shocks (bottom) are compared in one cell. spike jitter for young CBA mice was $0.031 \pm 0.012 \mathrm{~ms}$ $(n=7)$, as compared to $0.083 \pm 0.023 \mathrm{~ms}(n=7)$ for old mice $(p=0.066)$. Spike jitter increased subsequently within the stimulus train, and showed greater variation for later shocks (note the changing size of the error bars, Fig. 5C). At all shock frequencies, spike jitter in cells from old DBA mice was less than that in cells from young DBA mice $(p<0.05$, two-way ANOVA), which probably reflected the shorter latencies in old DBA mice. When spike jitter was normalized to the mean spike latency for each pulse in the train, no agerelated difference in spike jitter was observed $(p>0.05$; $n=11$, 13) (Fig. 5B). The spike jitter was not significantly different between young and old CBA mice $(p>0.05 ; n=7,7)$ when tested with shock trains at 100 and $300 \mathrm{~Hz}$, although it was slightly smaller in young CBA mice than in old CBA mice at $200 \mathrm{~Hz}$.

\section{Spike entrainment}

Spike entrainment for high-frequency shocks in CBA mice was significantly better overall than that in agematched DBA mice $(p<0.001$ for both young and old animals), perhaps reflecting a strain difference. However, a significant group difference for spike entrainment ( $p=0.01$, two-way ANOVA) was observed between young and old DBA mice at $100 \mathrm{~Hz}$ (Fig. 6A). No similar age-related entrainment decrease was seen in CBA mice $(p=0.15)$. At $100 \mathrm{~Hz}$, the average entrainment index for the first 10 shocks in the train was not significantly different ( $p=0.29, t$-test). However, for the second 10 shocks in the train, the old DBA mice showed poorer entrainment to the stimulus than young DBA mice $(p<0.0001$, Fig. $6 \mathrm{~A}$ inset). The overall entrainment was not significantly different between young and old DBA mice at higher shock frequencies (200 and $300 \mathrm{~Hz}$ ). This may reflect a floor effect, because there was a greater decrease in entrainment for subsequent shocks at higher shock frequencies in all groups (Figs. 6B, C). In both DBA and CBA mice, the entrainment index for later pulses could fall below 0.5 , even though the cells were capable of firing reliably at rates up to $300 \mathrm{~Hz}$ with current injection (Fig. 6C inset). This result indicates that the decreased entrainment to EPSPs is not attributable to changes in intrinsic firing mechanisms. At $300 \mathrm{~Hz}$, strong synaptic depression interacted with the relative refractory period of the spike resulted in an alternating pattern of spikes (Fig. 6C), similar to that seen in avian nucleus magnocellularis (NM) neurons with high-frequency stimulation (Reyes et al. 1994).

\section{Synaptic depression}

One explanation for the decreased entrainment at $100 \mathrm{~Hz}$ in old DBA mice could be that the depression 


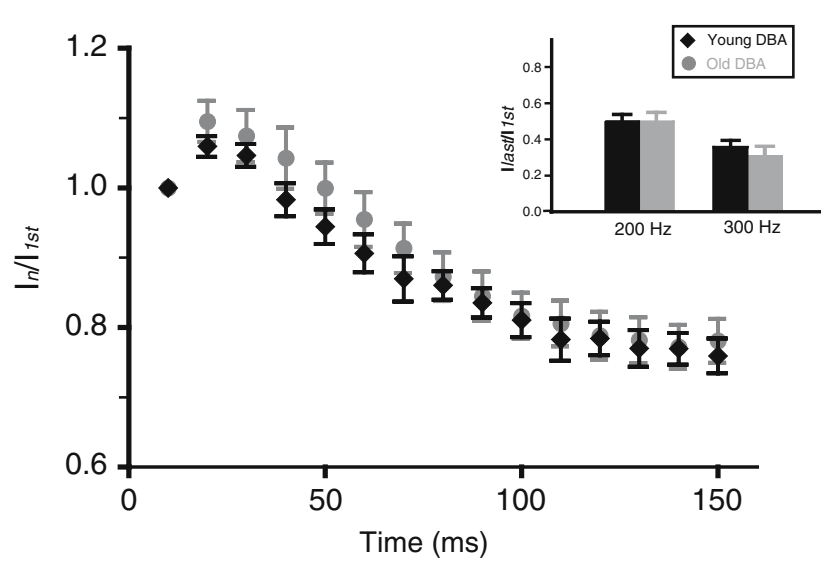

FIG. 7. Synaptic depression in DBA mice. Synaptic depression was measured by normalizing EPSC amplitudes to the first EPSC in the train. There was no difference between young and old DBA mice. Inset: final depression levels for 200 and $300 \mathrm{~Hz}$ shocks.

of EPSCs in DBA mice might show a frequencydependent difference between young and old animals. To test this idea, we measured synaptic depression of EPSCs under voltage clamp with the same stimulation pattern, at $33^{\circ} \mathrm{C}$. As previously shown in neurons of avian nuclear magnocellularis (Lawrence and Trussell 2000; Brenowitz and Trussell 2001) and mouse medial nucleus of the trapezoid body (MNTB) (Joshi and Wang 2002), synaptic responses at the endbulb of Held depress in a stimulus-frequency dependent manner. The initial evoked EPSC amplitudes were not different between young and old DBA mice $(5.8 \pm 2.0$ vs. $6.0 \pm$ $1.2 \mathrm{nA})$. Synaptic responses were reduced to $\sim 75 \%$, $45 \%$, and $30 \%$ of the initial response level at the end of shock train for 100, 200, and $300 \mathrm{~Hz}$, respectively. There was no difference in synaptic depression between young and old DBA mice at $100 \mathrm{~Hz}$ (Fig. 7), nor were there any differences at 200 and $300 \mathrm{~Hz}$ stimulus frequencies (upper inset). Similar results were observed when synaptic depression was measured at room temperature (as in all other experiments in this study) with a shorter train of five pulses at $100 \mathrm{~Hz}(0.48 \pm 0.05, n=19$, young vs. $0.54 \pm 0.05, n=9$, old; $p=0.48)$. At room temperature, EPSCs attain a steady-state amplitude at the end of five pulses at $100 \mathrm{~Hz}$ (not shown). Thus, we conclude that the decreased entrainment in old DBA mice at $100 \mathrm{~Hz}$ cannot be attributed to a difference in synaptic depression.

\section{DISCUSSION}

We examined the temporal coding capability of the AVCN bushy neurons in a mouse model of early-onset hearing loss. An increase in AP threshold along with an increase in the depth of the AP after hyperpolarization and the number of APs produced by $300 \mathrm{pA}$ depolarizing current pulses were the significant changes in intrinsic membrane properties found in hearingimpaired old DBA mice. In addition, the ability of the cells to fire reliably during trains of EPSPs at $100 \mathrm{~Hz}$ was significantly reduced in hearing-impaired DBA mice. The latency of APs to ANF stimulation was $0.46 \mathrm{~ms}$ shorter than normal in old DBA mice, and this was not caused by a change in low-voltage-activated $\mathrm{K}^{+}$conductance, but it was associated with a shorter EPSC latency. No significant change in spike jitter was observed between normal-hearing young and impaired hearing old DBA mice when spike jitter was normalized to the latency. The observed changes do not appear to be simply age-related, as there were no differences in intrinsic membrane properties, AP entrainment, or spike latency in age-matched CBA mice with normal hearing.

Despite a 20-dB increase in click ABR threshold, the age-related hearing loss in DBA mice produced some minor changes in intrinsic excitability of the HF bushy cells. The pattern of changes in electrical excitability that we observed did not match with those from previous reports, which examined hearing loss produced by cochlear ablation. For example, cochlear ablation resulted in small (but significant) changes in RMP, input resistance, action potential AHP (Francis and Manis 2000), and AP height (Lu et al. 2004). In the present study, no evidence for changes in RMP or input resistance was observed in HF cells of old, hearing-impaired DBA mice. The increase in action potential AHP was opposite to what was reported in cochlear ablated rats (Francis and Manis 2000). In addition, unlike cochlear-ablated rats (Francis and Manis 2000), the AP threshold was significantly elevated in old DBA mice in this study. This result confirms our previous observation in which recordings were made at $33^{\circ} \mathrm{C}$ (Wang and Manis 2005). The AP threshold elevation was also reported in acutely cochlear ablated chick NM neurons (Lu et al. 2004). Furthermore, multiple spiking of bushy neurons in response to large depolarizing currents indicates a reduction of $g_{\mathrm{KLV}}$ in hearing-impaired old DBA mice. Interestingly, a similar reduction in $g_{\mathrm{KLV}}$ has been reported in cochlear-ablated chick NM neurons (protein expression) (Lu et al. 2004) and in congenitally deaf mouse MNTB neurons (current density) (Leao et al. 2004). The different aspects of changes in intrinsic excitability observed in this study as compared to previous reports may reflect the different nature of "hearing loss." The progressive hearing loss studied here should cause a gradual change in auditory nerve activity, and at these ages, does not cause synaptic degeneration (Willott and Bross 1996). Cochlear ablation, on the other hand, immediately eliminates all auditory input to the cochlear nucleus neurons, leading to severe presynaptic terminal and fiber degeneration in the cochlear 
nucleus (Tucci et al. 1987; Born and Rubel 1988; Born et al. 1991; Benson et al. 1997).

The systematic latency difference between young and old high-frequency bushy cells in DBA mice was quite striking. We were able to directly compare spike latency and synaptic EPSC latency in the same set of cells, and found that there was a direct correlation between EPSC latency and spike latency. No correlation of the EPSC amplitude and the spike latency was found (Fig. 3B). Thus the spike latency difference appears to be principally related to axonal conduction velocity and/or synaptic delay. The source of this conduction speed difference is not clear although it is likely attributable to continued myelination (Romand and Romand 1990); or possibly continued maturation of $\mathrm{Na}^{+}$channels at the node of Ranvier in the auditory nerve. Interestingly, the second 10 pulses of the $100-\mathrm{Hz}$ stimulation in older CBA mice showed slightly shorter latency as well. Another possibility is that the hearing loss produces a compensatory increase in $\mathrm{Na}^{+}$channel density in the ANF, as reported after axotomy in dorsal root ganglion neurons (Cummins and Waxman 1997; Waxman et al. 1999; Abdulla and Smith 2002; Black et al. 2004).

The EPSC delay (measured at the peak) is somewhat smaller than the spike delay (also measured at the peak). Thus we also considered whether $g_{\mathrm{KLV}}$ contributed to the spike delay, because our current clamp data suggest that bushy cells in hearing-impaired VCN have reduced $g_{\mathrm{KLV}}$, as deduced from the observation that cells in old DBA mice tend to fire more APs when injected with a large $(300 \mathrm{pA})$ depolarizing current. The strength of $g_{\mathrm{KLV}}$ can have two opposing effects for EPSP to reach spike threshold. On one hand, it can oppose the depolarizing $\mathrm{Na}^{+}$conductance, and thus slow the rise to firing threshold. On the other hand, $g_{\mathrm{KLV}}$ shortens the EPSP rise time (Rothman and Manis 2003a; Fig. 6) because it largely determines the membrane time constant at rest. Our results indicate that across a reasonable range of $g_{\mathrm{KLV}}$, spike latency was minimally affected. However, we can not rule out the possibility that the lack of $g_{\mathrm{KLV}}$ effect on spike latency is attributable to remotely located $g_{\mathrm{KLV}}$ that can not be affected by dynamic clamp.

The spike jitter is clearly sensitive to stimulus rate. Thus it probably reflects $\mathrm{Na}^{+}$channel fluctuation during high rate of activity (Rubinstein 1995; Matsuoka et al. 2001) as well as jitter in the initiation of AP due to inactivation of $\mathrm{Na}^{+}$channels in the bushy cell. The first spike jitter was very similar between young and old DBA mice (Fig. 5A). However, the overall spike jitter in old DBA mice is slightly, but significantly, less than that in young DBA mice (Fig. 5C). During early development, there is a systematic improvement of spike timing jitter in avian
NM neurons (Brenowitz and Trussell 2001) and mammalian MNTB neurons (Taschenberger and von Gersdorff 2000). Thus the reduced jitter in old DBA mice could be explained as continued development. However, the data from CBA mice do not support this idea. Not only does the spike jitter not decrease between P22 and P45 in CBA mice, but it is slightly better in P22 CBA mice (Fig. 5A). The extra jitter in young DBA mice could be a result of elevated voltage-gated $\mathrm{Na}^{+}$current fluctuation at the newly formed axon nodes of Ranvier (Rubinstein, 1995), or may simply reflect the longer spike latency in young DBA mice. When the jitter was normalized to spike latency, there was no difference between the young and old DBA mice (Fig. 5B).

Our functional analysis of the ability of bushy cells to fire reliably to repetitive auditory nerve shocks revealed differences between DBA and CBA mice. Overall, bushy cells from CBA mice appear to entrain better than those from DBA mice in all 3 shock frequencies tested. Nevertheless, although the HF bushy cells in old DBA mice retain their ability for precise spike timing, entrainment to high-frequency stimuli could not be sustained during a long stimulus train. Despite decreased entrainment, bushy cells are capable of firing APs of up to $300 \mathrm{~Hz}$ in response to current pulses (Fig. 6C, inset). Thus, the decreased entrainment to $100 \mathrm{~Hz}$ ANF stimulation in bushy cells from hearing-impaired DBA mice suggests a deterioration of the cell's ability to follow sustained highfrequency excitatory synaptic input. The increased AP firing threshold (Table 1) (also Lu et al. 2004; Wang and Manis 2005) is likely a major contributor of the reduced entrainment. Entrainment could also be influenced by other factors, including a decrease in the input resistance in the depolarizing direction (Francis and Manis 2000; Lu et al. 2004), or the activation of a slowly developing conductance that shunts the EPSP, for example, a $\mathrm{Cl}^{-}$conductance from inhibitory inputs (Wu and Oertel 1986; Funabiki et al., 1998). How ever, local inhibition by D-stellate cells does not appear to be important, because application of $1 \mu \mathrm{M}$ strychnine, which blocks glycinergic synapses in AVCN (Wu and Oertel 1986; Harty and Manis 1996), did not enhance entrainment (data not shown). We can not rule out the influence of GABAergic synaptic input, although since no inhibitory postsynaptic potentials (IPSPs) were visible in the presence of strychnine, this seems unlikely.

Evoked synaptic current amplitude, synaptic depression, or asynchronous vesicular release could play a role in shaping the response of VCN bushy cells to high-frequency afferent activity. Our data show no difference in synaptic depression between young and old DBA mice (Fig. 7). We also show that the synaptic current in old DBA mice is not different 
from that in young DBA mice, consistent with our previous study (Wang and Manis 2005). Thus synaptic depression does not appear to play a role in the entrainment decrease at $100 \mathrm{~Hz}$. On the other hand, in spite of high safety margins for suprathreshold synaptic transmission between the ANF and bushy cell, the spike entrainment of bushy cells to nerve stimulation at 200 and $300 \mathrm{~Hz}$ drops to levels below 0.5 in both DBA and CBA mice. As an interesting comparison, simultaneous pre- and postsynaptic recordings from mice in vivo have suggested that about $50 \%$ of presynaptic spikes fail to trigger a postsynaptic spike (Pfeiffer 1966; Kopp-Scheinpflug et al. 2002). Although part of this failure can be attributed to inhibitory inputs, part may reflect the effect of synaptic depression.

In conclusion, we have demonstrated that the substantial hearing loss in DBA mice leads to changes in intrinsic membrane excitability of AVCN principal neurons. A functional assay revealed a reduction of the ability of bushy cells to entrain to high-frequency AN input because of increased AP firing threshold. This decrease in entrainment in high-frequency bushy cells of old DBA mice would be predicted to affect the processing of amplitude modulated sounds, which may be used as temporal cues for sound localization in mice (Henry 2000; Walton et al. 2002; Allen et al. 2006).

\section{ACKNOWLEDGMENT}

This study was supported by NIDCD grants R01DC04551 to PBM and F32DC04979 to Y.W.

\section{REFERENCES}

Abdulla FA, SMITH PA. Changes in $\mathrm{Na}(+)$ channel currents of rat dorsal root ganglion neurons following axotomy and axotomy-induced autotomy. J. Neurophysiol. 88:2518-2529, 2002.

Allen P, Muldrow A, Rivoli PJ, John AS, Ison JR. Age-related loss of behavioral ability to track ongoing but not initial SAM envelope in $\mathrm{CBA} / \mathrm{Caj}$ mice with intact modulation transfer functions. ARO Midwinter Meeting, Baltimore, MD. 2006.

Benson CG, Gross JS, Suneja SK, Potashner SJ. Synaptophysin immunoreactivity in the cochlear nucleus after unilateral cochlear or ossicular removal. Synapse 25:243-257, 1997.

Berglund AM, Brown MC. Central trajectories of type II spiral ganglion cells from various cochlear regions in mice. Hear. Res. 75:121-130, 1994.

Black JA, Liu S, Tanaka M, Cummins TR, Waxman SG. Changes in the expression of tetrodotoxin-sensitive sodium channels within dorsal root ganglia neurons in inflammatory pain. Pain 108: 237-247, 2004.

BORN DE, Rubel EW. Afferent influences on brain stem auditory nuclei of the chicken: presynaptic action potentials regulate protein synthesis in nucleus magnocellularis neurons. J. Neurosci. 8:901-919, 1988.
Born DE, Durham D, Rubel EW. Afferent influences on brainstem auditory nuclei of the chick: nucleus magnocellularis neuronal activity following cochlea removal. Brain Res. 557:37-47, 1991.

Brenowitz S, Trussell LO. Maturation of synaptic transmission at end-bulb synapses of the cochlear nucleus. J. Neurosci. 21: 9487-9498, 2001.

Brew HM, Forsythe ID. Two voltage-dependent $\mathrm{K}^{+}$conductances with complementary functions in postsynaptic integration at a central auditory synapse. J. Neurosci. 15:8011-8022, 1995.

Cao X, Oertel D. Voltage-sensitive conductances in bushy cells of the ventral cochlear nucleus of mice. Abstract, Assoc Res Otol 29, 2006.

Cummins TR, WAXman SG. Downregulation of tetrodotoxin-resistant sodium currents and upregulation of a rapidly repriming tetrodotoxin-sensitive sodium current in small spinal sensory neurons after nerve injury. J. Neurosci. 17:3503-3514, 1997.

Dorval AD, Christini DJ, White JA. Real-time Linux dynamic clamp: a fast and flexible way to construct virtual ion channels in living cells. Ann. Biomed. Eng. 29:897-907, 2001.

Ehret G. Psychoacoustics. In: Willot JF (ed) The Auditory Psychobiology of the Mouse. Charles C. Thomas, Springfield, IL, 1983.

Francis HW, Manis PB. Effects of deafferentation on the electrophysiology of ventral cochlear nucleus neurons. Hear. Res. 149:91-105, 2000.

Funabiki K, Koyano K, OHMori H. The role of GABAergic inputs for coincidence detection in the neurones of nucleus laminaris of the chick. J. Physiol. 508 ( Pt 3):851-869, 1998.

Gardner SM, Trussell LO, Oertel D. Time course and permeation of synaptic AMPA receptors in cochlear nuclear neurons correlate with input. J. Neurosci. 19:8721-8729, 1999.

Gardner SM, Trussell LO, Oertel D. Correlation of AMPA receptor subunit composition with synaptic input in the mammalian cochlear nuclei. J. Neurosci. 21:7428-7437, 2001.

HaRTY TP, MANis PB. Glycine-evoked currents in acutely dissociated neurons of the guinea pig ventral cochlear nucleus. J. Neurophysiol. 75:2300-2311, 1996.

Heffner RS, Gimseong K, Heffner HE. Focus: sound-localization acuity changes with age in C57BL/6J mice. In: Willot JF (ed) Handbook of Mouse Auditory Research: From Behavior to Molecular Biology. CRC Press, Boca Raton, FL, pp. 31-35, 2001.

HENRY KR. Low-frequency acoustic modulations generated by the high-frequency portion of the cochlea, noninvasively recorded from the scalp of mice (Mus musculus). J. Comp. Psychol. 114:22-35, 2000.

ISAACSON JS, WALMSLEY B. Counting quanta: direct measurements of transmitter release at a central synapse. Neuron 15:875-884, 1995.

IsaACSON JS, Walmsley B. Amplitude and time course of spontaneous and evoked excitatory postsynaptic currents in bushy cells of the anteroventral cochlear nucleus. J. Neurophysiol. 76: 1566-1571, 1996.

Ison JR, Allen P. A diminished rate of "physiological decay" at noise offset contributes to age-related changes in temporal acuity in the CBA mouse model of presbycusis. J. Acoust. Soc. Am. 114:522-528, 2003.

Joris PX, CARney LH, SMith PH, Yin TC. Enhancement of neural synchronization in the anteroventral cochlear nucleus. I. Responses to tones at the characteristic frequency. J. Neurophysiol. 71:1022-1036, 1994.

Joshi I, WANG LY. Developmental profiles of glutamate receptors and synaptic transmission at a single synapse in the mouse auditory brainstem. J. Physiol. 540:861-873, 2002.

KACHAR B. Asymmetric illumination contrast: a method of image formation for video light microscopy. Science 227:766-768, 1985.

Kopp-Scheinpflug C, Dehmel S, Dorrscheidt GJ, Rubsamen R. Interaction of excitation and inhibition in anteroventral cochlear nucleus neurons that receive large endbulb synaptic endings. J. Neurosci. 22:11004-11018, 2002. 
LaWrence JJ, Trussell LO. Long-term specification of AMPA receptor properties after synapse formation. J. Neurosci. 20: 4864-4870, 2000.

Leao RN, Berntson A, Forsythe ID, Walmsley B. Reduced lowvoltage activated $\mathrm{K}^{+}$conductances and enhanced central excitability in a congenitally deaf $(\mathrm{dn} / \mathrm{dn})$ mouse. J. Physiol. 559: 25-33, 2004.

Lu Y, Monsivais P, Tempel BL, Rubel EW. Activity-dependent regulation of the potassium channel subunits Kv1.1 and Kv3.1. J. Comp. Neurol. 470:93-106, 2004.

MAnis PB, MARX SO. Outward currents in isolated ventral cochlear nucleus neurons. J. Neurosci. 11:2865-2880, 1991.

Matsuoka AJ, Rubinstein JT, Abbas PJ, Miller CA. The effects of interpulse interval on stochastic properties of electrical stimulation: models and measurements. IEEE Trans. Biomed. Eng. 48:416-424, 2001.

Muller M, Hunerbein K, Hoidis S, Smolders JW. A physiological place-frequency map of the cochlea in the CBA/J mouse. Hear. Res. 202:63-73, 2005.

Nelson PB, Thomas SD. Gap detection as a function of stimulus loudness for listeners with and without hearing loss. J. Speech Lang. Hear. Res. 40:1387-1394, 1997.

OERTEL D. Synaptic responses and electrical properties of cells in brain slices of the mouse anteroventral cochlear nucleus. J. Neurosci. 3:2043-2053, 1983.

OERTEL D. Encoding of timing in the brain stem auditory nuclei of vertebrates. Neuron. 19:959-962, 1997.

Paolini AG, FitzGerald JV, Burkitt aN, Clark GM. Temporal processing from the auditory nerve to the medial nucleus of the trapezoid body in the rat. Hear. Res. 159:101-116, 2001.

PfEIfFER RR. Classification of response patterns of spike discharges for units in the cochlear nucleus: tone-burst stimulation. Exp. Brain Res. 1:220-235, 1966.

RAMAN IM, TRUSSELl LO. The kinetics of the response to glutamate and kainate in neurons of the avian cochlear nucleus. Neuron. 9:173-186, 1992.

Rathouz M, Trussell L. Characterization of outward currents in neurons of the avian nucleus magnocellularis. J. Neurophysiol. 80:2824-2835, 1998.

ReYes AD, Rubel EW, Spain WJ. Membrane properties underlying the firing of neurons in the avian cochlear nucleus. J. Neurosci. 14:5352-5364, 1994.

Romand MR, Romand R. Development of spiral ganglion cells in mammalian cochlea. J. Electron. Microsc. Tech. 15:144-154, 1990.

Rothman JS, Manis PB. The roles potassium currents play in regulating the electrical activity of ventral cochlear nucleus neurons. J. Neurophysiol. 89:3097-3113, 2003a.

Rothman JS, Manis PB. Kinetic analyses of three distinct potassium conductances in ventral cochlear nucleus neurons. J. Neurophysiol. 89:3083-3096, 2003b.

Rothman JS, Manis PB. Differential expression of three distinct potassium currents in the ventral cochlear nucleus. J. Neurophysiol. 89:3070-3082, 2003c.

Rubinstein JT. Threshold fluctuations in an $\mathrm{N}$ sodium channel model of the node of Ranvier. Biophys. J. 68:779-785, 1995.

SMITH PH, JoRIS PX, YIN TC. Projections of physiologically characterized spherical bushy cell axons from the cochlear nucleus of the cat: evidence for delay lines to the medial superior olive. J. Comp. Neurol. 331:245-260, 1993.

SNELL KB, Frisina DR. Relationships among age-related differences in gap detection and word recognition. J. Acoust. Soc. Am. 107:1615-1626, 2000.

Taschenberger H, von GersdorfF H. Fine-tuning an auditory synapse for speed and fidelity: developmental changes in presynaptic waveform, EPSC kinetics, and synaptic plasticity. J. Neurosci. 20:9162-9173, 2000.

Trussell LO. Synaptic mechanisms for coding timing in auditory neurons. Annu. Rev. Physiol. 61:477-496, 1999.

Tucci DL, Born DE, Rubel EW. Changes in spontaneous activity and CNS morphology associated with conductive and sensorineural hearing loss in chickens. Ann. Otol. Rhinol. Laryngol. 96:343-350, 1987.

Walton JP, Frisina RD, O’Neill WE. Age-related alteration in processing of temporal sound features in the auditory midbrain of the CBA mouse. J. Neurosci. 18:2764-2776, 1998.

Walton JP, Simon H, Frisina RD. Age-related alterations in the neural coding of envelope periodicities. J. Neurophysiol. 88: 565-578, 2002.

WANG Y, Manis PB. Synaptic transmission at the cochlear nucleus endbulb synapse during age-related hearing loss in mice. J Neurophysiol. 94:1814-1824, 2005.

Waxman SG, Cummins TR, Dib-HajJ S, Fjell J, Black JA. Sodium channels, excitability of primary sensory neurons, and the molecular basis of pain. Muscle Nerve 22:1177-1187, 1999.

Willott JF, Bross LS. Morphological changes in the anteroventral cochlear nucleus that accompany sensorineural hearing loss in DBA/2J and C57BL/6J mice. Brain Res. Dev. Brain Res. 91:218-226, 1996.

Willott JF, ERWAy LC. Genetics of age-related hearing loss in mice. IV. Cochlear pathology and hearing loss in 25 BXD recombinant inbred mouse strains. Hear. Res. 119:27-36, 1998.

Wu SH, OERTEL D. Inhibitory circuitry in the ventral cochlear nucleus is probably mediated by glycine. J. Neurosci. 6:2691-2706, 1986.

ZHeng QY, Johnson KR, ERWAY LC. Assessment of hearing in 80 inbred strains of mice by ABR threshold analyses. Hear. Res. 130:94-107, 1999. 